\title{
A 5-HT antagonist (UP 26-91) versus codeine and placebo in a human experimental pain study
}

Lars Arendt-Nielsen $\mathrm{PhD}^{1}$, Poul Pedersen $\mathrm{MD}^{2}$, Lars Poulsen $\mathrm{PhD} \mathrm{MD}^{2}$, Ole Kæseler Andersen $\mathrm{PhD}^{1}$, Peter Bjerring PhD MD Isabelle Coste $\mathrm{MD}^{4}$, Jorge Insuasty $\mathrm{MD}^{4}$, Søren Sindrup PhD MD${ }^{5}$, Asbjørn Mohr Drewes PhD MD ${ }^{2}$

L Arendt-Nielsen, P Pedersen, L Poulsen, et al.

A 5-HT antagonist (UP 26-91) versus codeine and placebo in a human experimental pain study.

Pain Res Manage 2000;14(2):135-140.

BACKGROUND: This double-blind, randomized, crossover study compared the potential analgesic effect of the serotonin receptor antagonist UP 26-91 (50 mg, $150 \mathrm{mg}$ and $300 \mathrm{mg}$ ) with that of codeine $(100 \mathrm{mg})$ and placebo by use of different human experimental pain models.

SUBJECTS AND METHODS: In experiment 1, pain detection and tolerance thresholds to heat, pressure and pain ratings during the cold pressor test were measured. In experiment 2, the pain threshold to single and repetitive (temporal summation) electrical sural nerve stimulation, and the pain intensity on a visual analogue scale to supra pain threshold electrical stimulation (stimulusresponse-function) were measured. Tests were performed before, and 1, 2 and $6 \mathrm{~h}$ after drug administration.

RESULTS: UP 26-91 did not show a marked effect on the experimental pain tests. Most of the variables tended to show a better effect from codeine than from placebo, but statistical significance for peak pain was only reached during the cold pressor test $(\mathrm{P}=0.011)$. CONCLUSIONS: In the present doses, the serotonin antagonist UP 26-91 had no effect on the experimental pain models applied.

Key Words: Codeine; Human experimental pain; Serotonin receptor antagonist

\section{Modèles expérimentaux de la douleur chez les humains : antagoniste 5-HT (UP 26-91), codéine et placebo}

DESCRIPTION : L'étude croisée, à double insu, avec hasardisation visait à comparer l'effet analgésique potentiel de l'antagoniste des récepteurs de la sérotonine UP 26-91 (50 mg, $150 \mathrm{mg}$ et $300 \mathrm{mg}$ ) à ceux de la codéine $(100 \mathrm{mg})$ et d'un placebo dans différents modèles expérimentaux de la douleur chez les humains.

SUJETS ET MÉTHODE : Dans la première expérience, on a mesuré les seuils de détection de la douleur et de la tolérance à la chaleur, à la pression et à la douleur durant l'épreuve au froid. Dans la deuxième expérience, on a mesuré le seuil de la douleur à une ou plusieurs stimulations nerveuses (sommation temporelle) ainsi que l'intensité de la douleur sur une échelle analogique visuelle à la suite d'une stimulation électrique dépassant le seuil de la douleur (stimulusréaction-fonction). Les épreuves ont été effectuées avant l'administration des médicaments ainsi que $1 \mathrm{~h}, 2 \mathrm{~h}$ et $6 \mathrm{~h}$ après.

RÉSULTATS : L'UP 26-91 n'a pas eu d'effet marqué sur la douleur dans les différentes épreuves. La plupart des variables ont eu tendance à mieux réagir à la codéine qu'au placebo, mais une différence significative sur le plan statistique concernant l'intensité maximale de la douleur n'a été enregistrée qu'avec l'épreuve au froid $(\mathrm{P}=0,011)$. CONCLUSIONS : L'antagoniste des récepteurs de la sérotonine UP 26-91, administré aux doses indiquées, n'a pas eu d'effet sur les modèles expérimentaux de la douleur.

\footnotetext{
${ }^{1}$ Center for Sensory-Motor Interaction, Aalborg University, Aalborg, Denmark; ${ }^{2}$ Department of Medicine, Aalborg Hospital, Aalborg, Denmark;

${ }^{3}$ Department of Dermatology, Aarhus University Hospital, Aarhus, Denmark; ${ }^{4}$ Department of Clinical Research, UPSA Laboratories, Rueil-

Malmaison, France; ${ }^{5}$ Department of Clinical Pharmacology, Odense University, Odense, Denmark

Correspondence and reprints: Prof Lars Arendt-Nielsen, Center for Sensory-Motor Interaction, Aalborg University, Fredrik Bajers Vej 7, D-3, DK-9220

Aalborg, Denmark. Telephone +45-96-35-88-30, fax +45-98-15-40-08, e-mail LAN@miba.auc.dk

Accepted for publication February 23, 2000. Accepted March 24, 2000
} 
$S^{c}$ erotonin (5-hydroxytryptamine [5-HT]) plays an important role in the modulation of nociceptive processes, probably in the spinal cord, brain stem and higher brain centres. Details of the interaction of 5-HT with nociception are not fully understood because the pharmacology of 5-HT is very complex (1). There is conflicting information in the pain literature on the antinociceptive effect of 5-HT agonists versus that of 5-HT antagonists (1). 5-HT exerts various actions in different tissues $(2,3)$ and acts on many different receptors (4). Inhibition of presynaptic reuptake of 5-HT is one of the possible action mechanisms of tricyclic antidepressants in the treatment of neurogenic pain (5). Furthermore, increased 5-HT release may also be responsible for some of the effect of the analgesic drug tramadol $(6,7)$.

UP 26-91-citrate (3-\{2 [4-(2,4 difluorophenyl) piperazin1-yl] ethylmercapto $\}$ triazolo $[4,3 \mathrm{a}]$ pyridine, citrate salt) is a new drug synthesized by Laboratoires UPSA (France). In vitro pharmacological studies have shown that UP 26-91 is a $5-\mathrm{HT}_{2}$ antagonist, and one of its metabolites, UP 26-93, is a partial 5-HT 1 and 5-HT 2 agonist. Moreover, UP 26-91 binds to benzodiazepine and to sigma receptors, and UP 26-93 binds to $5-\mathrm{HT}_{3}$ receptors. In animal experiments, UP 26-91 has shown analgesic activity in models of acute pain (hot plate test, tail pinch test, kaolin-induced arthritis) and neuropathic pain (ligation of the sciatic nerve). Furthermore, UP 26-91 has shown antidepressant activity on the behavioural despair test (internal reports, Laboratoires UPSA).

The aim of the present study was to test the potential analgesic effect of different doses of UP 26-91 in selected human experimental pain models. The screening for analgesic effects in such models may be important both to support the hypothesis that the compound is analgesic in humans and to obtain an impression of the appropriate doses in later clinical studies. By using a variety of stimulus modalities, it is possible to get a detailed description of how a given drug modulates transmission and processing along the pain pathways (8). Within the past decade, human experimental pain models have been developed to detect the analgesic effect of centrally acting drugs. Thus, pain tolerance thresholds to heat and pressure stimuli and pain during the cold pressor test (9), as well as thresholds for the withdrawal reflex to electrical stimulation $(10,11)$, are affected by opioids. In these tests, however, the tricyclic antidepressant imipramine only shows an effect on pressure pain tolerance and psychophysical pain thresholds to electrical stimulation (12). A model for human temporal summation has been developed (13). Pain summation is significantly changed by imipramine (12) and ketamine (14), and this model may, therefore, indicate whether a given drug has an effect on neurogenic pain. Thus, in current studies, various experimental models have been chosen for two double-blind, randomized, Latin square crossover experiments with UP 26-91 against an active control (codeine, which acts through its metabolic transformation to morphine) and placebo in healthy volunteers.

We hypothesized that UP 26-91 could show an analgesic effect on different standardized pain stimuli compared with that of a known analgesic and placebo.

\section{SUBJECTS AND METHODS}

\section{Subjects}

Experiment 1 comprised 15 healthy male volunteers. Experiment 2 comprised 12 healthy male volunteers. None of the volunteers participated in both experiments. Codeine acts through its metabolic transformation to morphine (15), and the demethylation of codeine to morphine depends on the genetically polymorphic enzyme CYP2D6 (16). Therefore, only subjects who extensively metabolize sparteine (17) and thus have an active form of CYP2D6 were included in the experiments.

The sparteine oxidation polymorphism results from differences in the activity of one isozyme of cytochrome P450. Polymorphic oxidation of the pharmacogenetic probe drug sparteine was used to discriminate between poor metabolizers (PM) and extensive metabolizers (EM). The oxidation of more than 20 clinically useful drugs has been shown to be under similar genetic control to that of sparteine/debrisoquine. Clinically, this polymorphism and, hence, the practice of phenotyping patients before treatment, are important when the elimination of the drug and/or its active metabolite is mainly determined by this enzyme.

Phenotyping was carried out on the basis of the metabolic ratio (MR) between sparteine and 2- and 5-dehydrosparteine (percentage of dose) in $12 \mathrm{~h}$ urine. The ratio ranged from 0.11 to 12.6 in EM and from 30 to 394 in PM. Urinary excretion of 2- and 5-dehydrosparteine also discriminated between PM and EM. Age, sex and smoking habits do not influence the MR.

The volunteers ranged in age from 21 to 29 years, in body weight from 55 to $90 \mathrm{~kg}$ and in height from 165 to $196 \mathrm{~cm}$. The volunteers gave their written informed consent before the study procedure, and the local Ethics Committees of Aarhus, Fyns and Nordjyllands Amt, and the Danish National Board of Health approved the experiment.

\section{Study design and medication}

In experiment 1, three dose levels of UP 26-91 (50, 150 and $300 \mathrm{mg}$ ) (Laboratoires UPSA) given as single oral doses were tested against a single oral dose of codeine $(100 \mathrm{mg})$ and placebo in a double-blind, randomized crossover design. The doses of UP 26-91 were chosen in accordance with a previous single dose tolerability study and to obtain a possible doseeffect relationship. The codeine dose corresponded to a previously used dose (15). The sequence of administration was determined according to a Latin square crossover design, and there was a washout period of at least two weeks between each of the five treatments.

The sequence of pain measures was as follows: warmth and heat pain thresholds, pressure pain detection and tolerance thresholds, and cold pressor test.

In experiment 2, UP 26-91 $300 \mathrm{mg}$, codeine $100 \mathrm{mg}$ and placebo were used; two weeks elapsed between medications.

The subjects were assigned to either morning or afternoon sessions, and pain tests were performed before, and 1,2 and $6 \mathrm{~h}$ after medication. Additional analgesic drugs or alcohol were not allowed $24 \mathrm{~h}$ before or during the study. 
The sequence of pain measures was as follows: the detection and pain thresholds for single electrical stimulation, the pain summation threshold and pain intensity rating of suprathreshold electrical stimulation.

\section{Pain tests}

Experiment 1 - Warmth threshold, heat pain detection threshold, and heat pain tolerance threshold: The warmth threshold, heat pain detection threshold, and heat pain tolerance thresholds were determined by a computerized version of the Termotest (Somedic AB, Sweden). This has previously been used in trials of analgesic efficacy $(7,9,12)$. The stimulation area was $2.5 \times 5 \mathrm{~cm}$. For all determinations, a baseline temperature of $35^{\circ} \mathrm{C}$ (warmth detection) or $38^{\circ} \mathrm{C}$ (heat pain detection and tolerance), a $1^{\circ} \mathrm{C} / \mathrm{s}$ rate of change and a cutoff of $52^{\circ} \mathrm{C}$ were applied. By pressing a button, the subject indicated when the pertinent threshold was reached. Each threshold was calculated as the average of five determinations performed with randomized intervals of 10 to $15 \mathrm{~s}$. The test areas were the volar aspect of the right (warmth and heat pain detection) and left forearm (heat pain tolerance).

Pressure pain thresholds: The pressure pain detection and tolerance thresholds were determined by an electronic pressure algometer (Somedic AB, Sweden). The stimulation area was $28 \mathrm{~mm}^{2}$, and the pressure was increased by $1.1 \mathrm{~N} / \mathrm{s}$. The stimulus was applied to the dorsal part of the middle phalanx of the second finger. The volunteers pressed a button when the sensation changed from pressure to pain (pain detection threshold) and when the maximum tolerable pain level (pain tolerance threshold) was reached. The thresholds were calculated as the mean of five determinations performed with randomized intervals of 10 to $15 \mathrm{~s}$.

Cold pressor test: The left hand was immersed in ice-chilled water $\left(0.9 \pm 0.3^{\circ} \mathrm{C}\right)$ that was continuously stirred by a pump. After a 2 min immersion, the subjects removed their hands from the water. An electronic visual analogue scale (VAS) (zero to 10 red lights) continuously rated the pain intensity and transformed it into an electrical signal $(0$ to $8 \mathrm{~V})$, which was sampled by a computer. From the recordings obtained, the peak pain intensity score and area under the pain intensity time curve (AUC) were determined (18).

Experiment 2 - Sural nerve electrical stimulation: The sural nerve was stimulated transcutaneously along its retromalleolar path by computer-controlled constant-current rectangular stimuli consisting of five pulses (each with a duration of $1 \mathrm{~ms}$ ). The five pulses were delivered as a burst (20 ms) at $200 \mathrm{~Hz}$ (single stimulation), or the burst was repeated four times with a frequency of $3 \mathrm{~Hz}$ (repetitive stimulation). The detection and pain thresholds for single stimulation were determined together with the pain summation threshold. The pain summation threshold to repetitive stimuli was determined by increasing the stimulus in steps of $0.2 \mathrm{~mA}$. When the volunteer experienced the fourth and fifth stimuli as painful, the threshold was reached. The first three or four stimuli in the series were not painful. The pain summation threshold was lower than the pain threshold to single stimuli due to central integration. Thresholds were deter-
TABLE 1

Mean $( \pm S D)$ plasma concentrations $(\mathrm{mg} / \mathrm{mL})$ of UP 26-91 and codeine observed during experiment 1 in 15 subjects UP 26-91 Codeine

\begin{tabular}{lcccc}
$\begin{array}{l}\text { Time after } \\
\text { administration }\end{array}$ & $\mathbf{5 0} \mathbf{~} \mathbf{~ g}$ & $\mathbf{1 5 0} \mathbf{~ m g}$ & $\mathbf{3 0 0} \mathbf{~} \mathbf{g}$ & $\mathbf{1 0 0} \mathbf{~} \mathbf{g}$ \\
\hline $1 \mathrm{~h}$ & $254 \pm 66$ & $702 \pm 525$ & $1010 \pm 518$ & $128 \pm 22$ \\
$2 \mathrm{~h}$ & $106 \pm 53$ & $484 \pm 429$ & $691 \pm 327$ & $103 \pm 31$ \\
$6 \mathrm{~h}$ & $4.8 \pm 6.2$ & $33.8 \pm 48.9$ & $87.4 \pm 82.5$ & $37 \pm 15$ \\
\hline
\end{tabular}

mined as the average of the thresholds determined in three ascending series of stimulation. A detailed description of these methods has been published previously (13).

Pain intensity rating of suprathreshold electrical stimulation: Pain intensity to single electric sural nerve stimulation, with a strength of 1.2, 1.4, 1.6 and 1.8 times the premedication pain threshold, was rated with the use of a VAS.

\section{Side effects}

The volunteers were asked to describe any side effects at regular intervals after drug intake on each study day, and the side effects were registered.

\section{Blood samples}

Blood samples for determining plasma concentrations of UP 26-91 were collected after each set of measurements in experiment 1 , and only $2 \mathrm{~h}$ after administration in experiment 2. The plasma was stored at $-20^{\circ} \mathrm{C}$ until analysis. The plasma concentration of UP 26-91 was determined by high pressure liquid chromatography with fluorimetric detection. The limit of determination was $1 \mathrm{mg} / \mathrm{mL}$.

\section{Data analysis and statistics}

Three-way ANOVA for repeated measures was used for analysis of the different parameters. The factors were treatment (drugs), parameter (thresholds, reflexes, etc) and time (after medication). Multiple pairwise post hoc comparisons of the parameters were performed with a nonparametric Student-Newman-Keuls test. Simple comparisons between baseline and a given postmedication value were done using the Wilcoxon rank test. The data are presented as mean values, and significance was accepted at $\mathrm{P}<0.05$.

\section{Pharmacokinetics}

\section{RESULTS}

Plasma concentrations of UP 26-91 are summarized in Table 1, with concentrations of codeine after an oral administration of $100 \mathrm{mg}$ codeine phosphate.

The concentrations of UP 26-91 measured in experiment 1 were nearly in accordance with previous results obtained in healthy, young volunteers during the first single dose tolerance study after taking $50 \mathrm{mg}, 150 \mathrm{mg}$ and $300 \mathrm{mg}$. A large interindividual variability was already described for UP 26-91, which is widely metabolized.

In experiment 2, concentrations of UP 26-91 and codeine were measured in 12 subjects $2 \mathrm{~h}$ after the administration of 


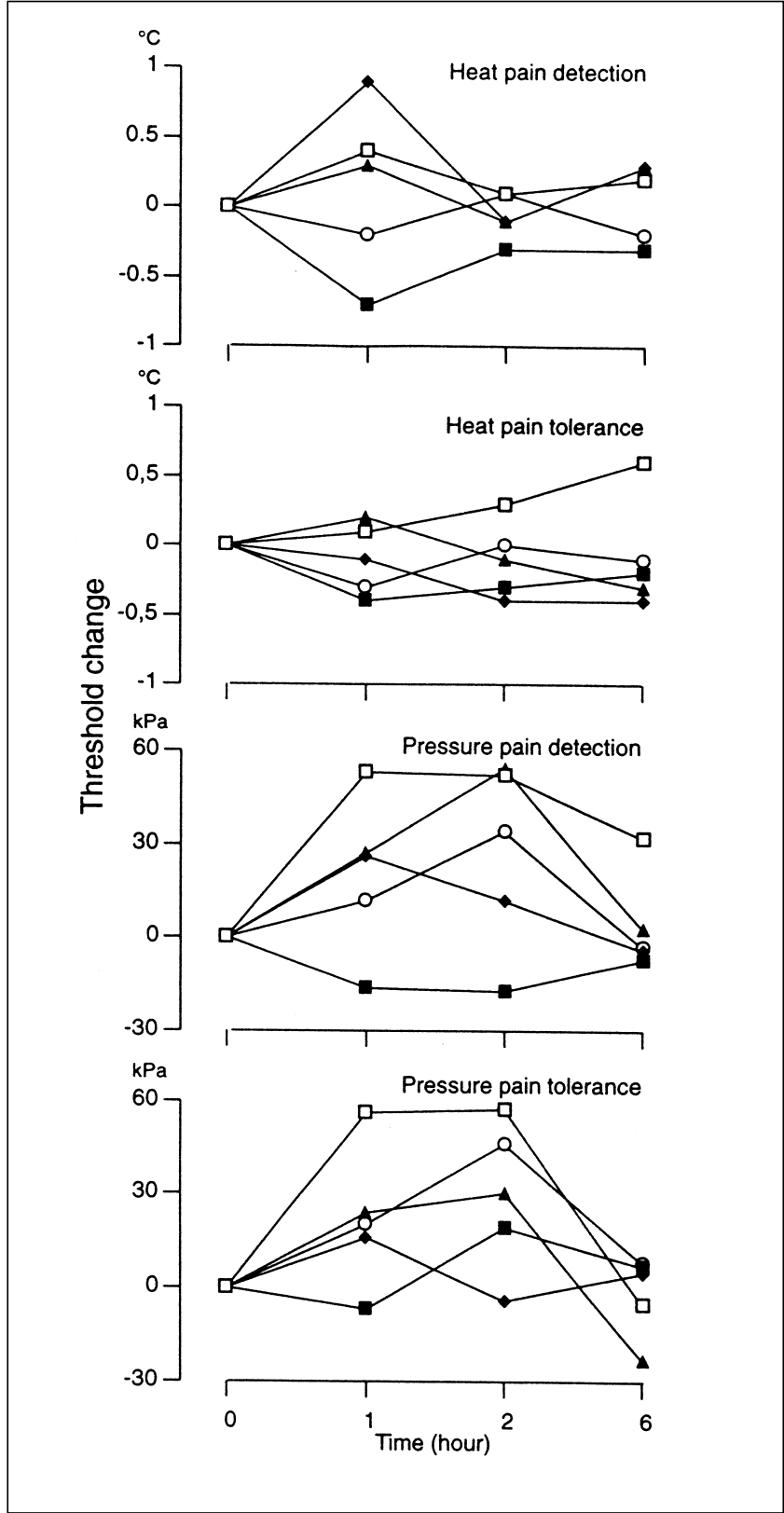

Figure 1) Postmedication (1, 2 and 6 h) threshold changes (mean) from baseline (0 h) with UP 26-91 $50 \mathrm{mg}(\mathbf{\Delta})$, UP 26-91 $150 \mathrm{mg}(\bullet)$, UP 26-91 $300 \mathrm{mg}(\boldsymbol{\square})$, codeine $100 \mathrm{mg}(\square)$ and placebo $(\bigcirc)$ for heat pain detection and tolerance, and pressure pain detection and tolerance (experiment 1 ). Tests were performed before, and 1, 2 and $6 \mathrm{~h}$ after medication

$300 \mathrm{mg}$ of UP $26-91$ or $100 \mathrm{mg}$ of codeine phosphate. The concentrations were essentially equivalent to those used in experiment 1.

\section{Side effects}

In experiment 1 , two subjects reported fatigue after taking UP 26-91 $50 \mathrm{mg}$. After taking the $150 \mathrm{mg}$ dose, one subject experienced fatigue, one subject experienced dizziness and one subject had symptoms of postural hypotension. After taking the $300 \mathrm{mg}$ dose, one subject experienced fatigue, three subjects experienced dizziness and one subject had symptoms of postural hypotension.

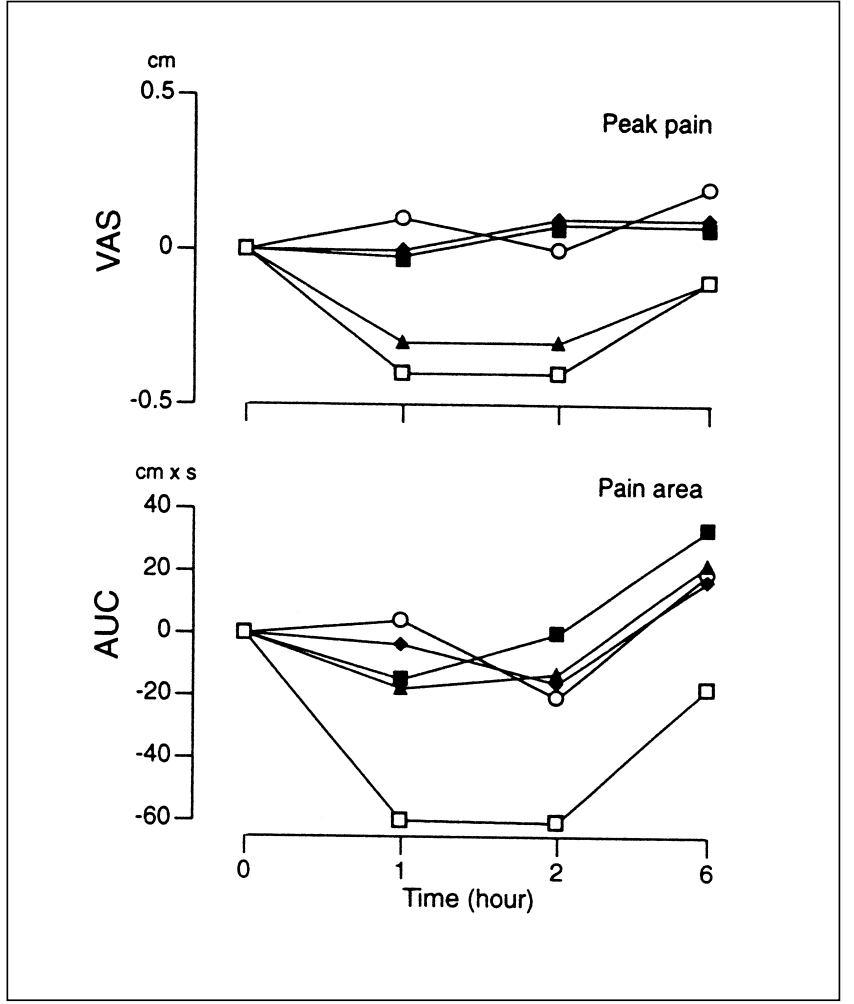

Figure 2) Postmedication (1, 2 and $6 \mathrm{~h}$ ) changes (mean) from baseline (0 h) with UP 26-91 $50 \mathrm{mg}(\boldsymbol{\Delta})$, UP 26-91 $150 \mathrm{mg}(\bullet)$, UP 26-91 $300 \mathrm{mg}$ $(\square)$, codeine $100 \mathrm{mg}(\square)$ and placebo $(\bigcirc)$ for peak pain and pain area during the cold pressor test (experiment 1 ). Tests were performed before, and 1, 2 and 6 h after medication. AUC Area under the curve; VAS Visual analogue scale

In experiment 2 , only one volunteer experienced fatigue and two persons reported malaise after taking UP 26-91 $300 \mathrm{mg}$. No serious adverse events were observed during the experiments.

\section{Pain tests}

Experiment 1: The baseline values (before medication) of the UP 26-91 $50 \mathrm{mg}$, UP 26-91 $150 \mathrm{mg}$, UP 26-91 $300 \mathrm{mg}$, codeine and placebo study days of warmth detection (37.4, 37.7, 37.4, 37.2 and $\left.37.3^{\circ} \mathrm{C}\right)$, heat pain detection $(43.3,43.1$, $43.2,43.2$ and $\left.43.1^{\circ} \mathrm{C}\right)$ and heat pain tolerance $(48.2,48.1$, $48.4,48.3$ and $48.7^{\circ} \mathrm{C}$ ) were not significantly different. Similarly no differences among the treatment arms were seen for baseline pressure pain detection $(457,447,471,420$ and $443 \mathrm{kPa}$ ), pressure pain tolerance $(656,648,628,644$ and $644 \mathrm{kPa})$, cold pressor peak pain $(8.0,8.0,8.0,7.7$ and $7.5 \mathrm{~cm})$ or cold pressor pain AUC $(670,660,675,668$ and $648 \mathrm{~cm} \times \mathrm{s})$. The warmth detection threshold was unaltered by the treatments. The mean changes from baseline for the other variables are shown in Figures 1 and 2. There was no effect of any of the doses of UP 26-91, whereas all variables tended to be affected by codeine. However, only the reduction in cold pressor peak pain reached statistical significance $(\mathrm{P}<0.01)$ (Table 2).

From the figures, it is evident that codeine exerted analgesic actions on various measures. The reason why this was not detected is that the statistical weakness introduced by having 
TABLE 2

\begin{tabular}{|c|c|c|}
\hline & $\mathbf{P}^{*}$ & $\begin{array}{c}\text { Actual } \\
\text { difference }\end{array}$ \\
\hline \multicolumn{3}{|c|}{ Heat pain threshold } \\
\hline Detection & 0.49 & - \\
\hline Tolerance & 0.068 & - \\
\hline \multicolumn{3}{|c|}{ Pressure pain threshold } \\
\hline Detection & 0.72 & - \\
\hline Tolerance & 0.24 & - \\
\hline \multicolumn{3}{|c|}{ Cold pressor pain } \\
\hline Peak & 0.011 & $\begin{array}{c}1 \text { and } 2 \mathrm{~h} ; \\
\text { codeine } \\
<\text { placebo }\end{array}$ \\
\hline AUC & 0.41 & - \\
\hline
\end{tabular}

five different treatment conditions. By performing a simple statistical comparison on codeine, significant changes in pressure pain detection, pressure pain tolerance and cold pressor pain AUC compared with baseline recordings were found.

Experiment 2: The baseline values (premedication) of the UP 26-91 $300 \mathrm{mg}$, codeine and placebo study days of electrical detection threshold $(0.83,0.75$ and $0.74 \mathrm{~mA})$, pain threshold (5.4, 6.5 and $6.3 \mathrm{~mA})$ and pain summation threshold (4.7, 6.2 and $4.9 \mathrm{~mA}$ ) were not significantly different. Also, no differences were seen for baseline VAS ratings at 1.2 (2.1, 2.1 and $2.1 \mathrm{~cm}), 1.4(2.4,2.5$ and $2.7 \mathrm{~cm}), 1.6(2.7,3.0$ and $2.8 \mathrm{~cm})$ or $1.8(3.2,3.4$ and $3.2 \mathrm{~cm})$ times the premedication pain threshold. The changes in sensation threshold and VAS ratings of supra pain threshold stimulation were unaltered by the treatments (Table 3 ). The mean changes from baseline for pain threshold and pain summation threshold are shown in Figure 3. No effect was found for any of UP 26-91 doses, whereas these variables tended to have a treatment effect on codeine. However, none of the differences reached statistical significance (Table 3).

Significant increases in pain thresholds to single and repeated stimulation were found by using a simple statistical comparison of codeine response to baseline.

\section{DISCUSSION}

Tests of new potentially analgesic drugs by human experimental pain models may serve several purposes. Initially, it may be possible to determine whether the drug has an analgesic effect at all and to predict the optimal dose range for clinical trials. Second, the delay from drug intake until onset and maximal effect can be determined under standardized conditions. Subsequent clinical trials may thus either be cancelled or performed with a suggested optimal design. The use of human experimental pain studies may thus bridge the gap
TABLE 3

Significance testing for pain tests in experiment 2 (UPSA 26-91 $300 \mathrm{mg}$, placebo and codeine $100 \mathrm{mg}$ )

\begin{tabular}{lcc}
\hline & P* & $\begin{array}{c}\text { Actual } \\
\text { difference }\end{array}$ \\
\hline $\begin{array}{l}\text { Single electrical stimulation } \\
\text { Sensation threshold }\end{array}$ & 0.09 & - \\
$\quad$ Pain threshold & 0.32 & - \\
VAS pain at 1.2 times threshold & 0.54 & - \\
VAS pain at 1.4 times threshold & 0.53 & - \\
VAS pain at 1.6 times threshold & 0.55 & - \\
$\quad$ VAS pain at 1.8 times threshold & 0.78 & - \\
Repetitive electrical stimulation & & \\
$\quad$ Pain summation threshold & 0.26 & \\
*Repeated measure ANOVA. VAS Visual analogue scale &
\end{tabular}

*Repeated measure ANOVA. VAS Visual analogue scale

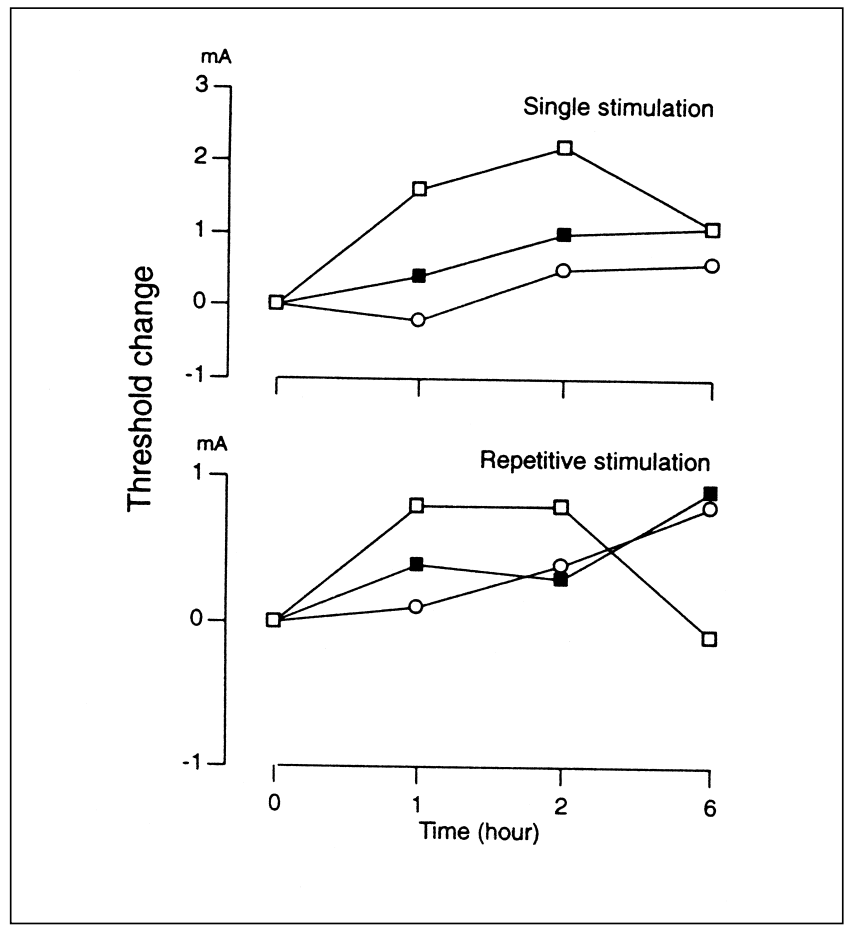

Figure 3) Postmedication (1, 2 and $6 \mathrm{~h}$ ) changes (mean) from baseline $(0 \mathrm{~h})$ with UP 26-91 $300 \mathrm{mg}(\mathbf{\square})$, codeine $100 \mathrm{mg}(\square)$ and placebo $(O)$ for pain thresholds to single and repetitive electrical sural nerve stimulation (experiment 2). Tests were performed before, and 1, 2 and $6 \mathrm{~h}$ after medication

between animal experiments and clinical trials with patients and thereby be an important tool in drug development.

The pain tests used in this study have previously substantiated the analgesic effect of tricyclic antidepressants (12) and ketamine (14), ie, analgesics with clearly different mechanisms of action. The reason for the missing effect of our positive control, codeine, was most likely related to the general study design, with five versus three different treatments and a similar number of volunteers (9), with accompanying reduced statistical power. However, the study used a Latin square crossover design. Thus, codeine effects were clearly found for a range of the tests (Figures 1-3), and simple statis- 
tical analysis showed that these changes were significant. Therefore, we assumed that the sensory test procedures were sufficiently sensitive. Willer (10) reported increased withdrawal reflex thresholds after sural nerve stimulation with morphine. Because codeine is supposed to act through metabolically formed morphine, it is expected to cause an increase in the reflex. We found no effect of codeine on pain and pain summation thresholds. This indicated that the levels of morphine achieved after codeine administration were too low to influence these pain measures. Imipramine or ketamine would have been more appropriate and positive controls $(12,14)$ in the present study because these substances are known to inhibit temporal summation, although this knowledge was not available when the study was planned.

UP 26-91 was completely without any detectable analgesic effect in both experiments. The reason for this finding is speculative. Maybe the doses of UP 26-91 were too low, ie, it may have been too restrictive only to use doses below the level that resulted in harmless side effects in some of the subjects in the previous single dose tolerability study. It is of course impossible to predict effective doses from the previous animal experiments with clear analgesic effects of UP 26-91.

It can also be suggested that multiple dosing should have been used because clinical experience with serotonergic drugs suggests that multiple dosing is required before adequate clinical effects are obtained. Another less plausible explanation for the lack of analgesic effect of UP 26-91 is that

\section{REFERENCES}

1. Jolas T, Aghajanian GK. Neurotensin and the serotonergic system. Prog Neurobiol 1997;52:455-68.

2. Fozard JR. Neuronal 5-hydroxytryptamine receptors in the periphery. Neuropharmacology 1984;23:1473-86.

3. Butcher LL, Woolf NJ. Cholinergic and serotonergic systems in the brain and spinal cord: anatomic organization, role in intracellular communication processes, and interactive mechanism. Prog Brain Res 1982;55:1-40.

4. Bradley PB, Engel G, Feniuk W, et al. Proposal for the classification and nomenclature of functional receptors for 5-hydroxytryptamine. Neuropharmacology 1986;25:563-576

5. Sindrup SH, Gram LF, Brøsen K, Eshøj O, Mogensen EF. The selective serotonin reuptake inhibitor paroxetine is effective in the treatment of diabetic neuropathy symptoms. Pain 1990;42:35-144.

6. Raffa RB, Friederich E, Reimann W, et al. Complementary and synergistic antinociceptive interaction between enantiomers of tramadol. J Pharmacol Exp Ther 1993;267:331-40.

7. Poulsen L, Arendt-Nielsen L, Brøsen K, Sindrup SH. The hypoalgesic effect of tramadol in relation to CYP2D6. Clin Pharmacol Ther 1996;60:636-44.

8. Arendt-Nielsen L. Induction and assessment of experimental pain from human skin, muscle, and viscera. In: Jensen TS, Turner JA, Wiesenfeld-Hallin Z, eds. Progress in Pain Research and Management. Seattle: IASP Press, 1997:393-425.

9. Poulsen L, Arendt-Nielsen L, Brøsen K, Gram LF, Pedersen KE, Sindrup SH. Codeine and morphine in extensive and poor metabolisers of sparteine: pharmacokinetics, analgesic effect and side effects. Eur J Clin Pharmacol 1996;51:289-95.

10. Willer JC. Studies on pain - Effect of morphine on a spinal the present pain models might not be suitable for measuring the analgesic effect of this new type of analgesic, although it is difficult to suggest tests that are more relevant. The experimental pain models used in the present study represent phasic versus tonic pain, pain detection versus pain tolerance and single versus repetitive stimulation. Furthermore, the models have substantiated the analgesic effect of drugs with different mechanisms of action. As of yet, there are no other human experimental data on the analgesic effect of UP 26-91.

No studies on the clinical applications of UP 26-91 have been published. With the present results, it is difficult to argue in support of performing a time consuming and expensive clinical trial on the analgesic effect of the drug, at least in the doses used here.

\section{CONCLUSIONS}

In doses that do not produce significant side effects, UP 26-91 showed no analgesic effect in pressure, thermal or electric pain models. The overall methodology is validated by a significant effect of codeine on cold pressor pain, although the effect of codeine is less clear than in previous studies. This is most likely due to less statistical power of the present study than that of previous investigations.

ACKNOWLEDGEMENTS: We thank Laboratoires UPSA, France, for providing the drugs for this study, and the Mermaid Institute, Denmark, for facilitating the contact.

nociceptive flexion reflex and related pain sensation in man. Brain Res 1985;331:105-14.

11. Petersen-Felix S, Arendt-Nielsen L, Bak P, Fischer M, Zbinden AM. Psychophysical and electrophysiological responses to experimental pain may be influenced by sedation: comparison of the effects of a hypnotic (propofol) and an analgesic (alfentanil). Br J Anaesth 1996;77:165-71.

12. Poulsen L, Arendt-Nielsen L, Brøsen K, Nielsen KK, Gram LF, Sindrup SH. The hypoalgesic effect of imipramine in different human experimental pain models. Pain 1995;60:287-93.

13. Arendt-Nielsen L, Brennum J, Sindrup SH, Bak P. Electrophysiological and psychophysical quantification temporal summation of the human nociceptive system. Eur J Appl Physiol 1994;68:266-73.

14. Arendt-Nielsen L, Petersen-Felix S, Fischer M, Bak P, Bjerring P, Zbinden AM. The effect of a NMDA-antagonist (Ketamine) on single and repeated nociceptive stimuli - a double-blind, placebo-controlled experimental human study. Anesth Analg 1995;81:63-8.

15. Sindrup SH, Brøsen K, Bjerring P, et al. Codeine increases pain thresholds to copper vapor laser stimulation in extensive but not in poor metabolizers of sparteine. Clin Pharmacol Ther 1990;48:686-93.

16. Yue QY, Svensson J-O, Alm C, Sjöqvist F, Säwe J. Codeine O-demethylation co-segregates with polymorphic debrisoquine hydroxylation. Br J Clin Pharmacol 1989;28:639-45.

17. Brøsen K, Otton SV, Gram LF. Sparteine oxidation polymorphism in Denmark. Acta Pharmacol Toxicol 1985;57:357-60.

18. Jones SF, McQuay HJ, Moore RA, Hand CW. Morphine and ibuprofen compared using the cold pressor test. Pain 1988;34:117-22. 


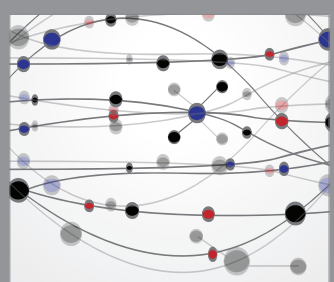

The Scientific World Journal
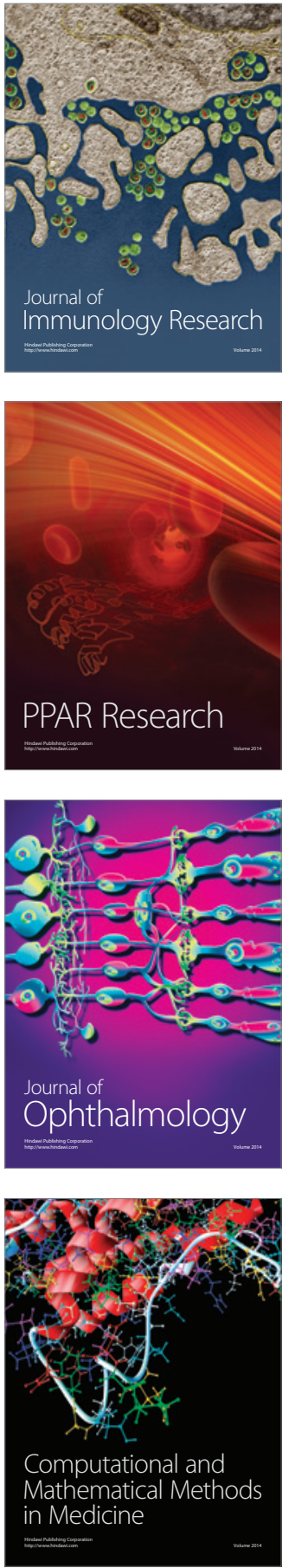

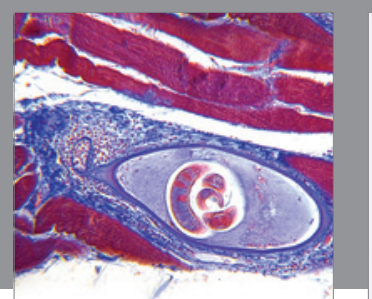

Gastroenterology Research and Practice

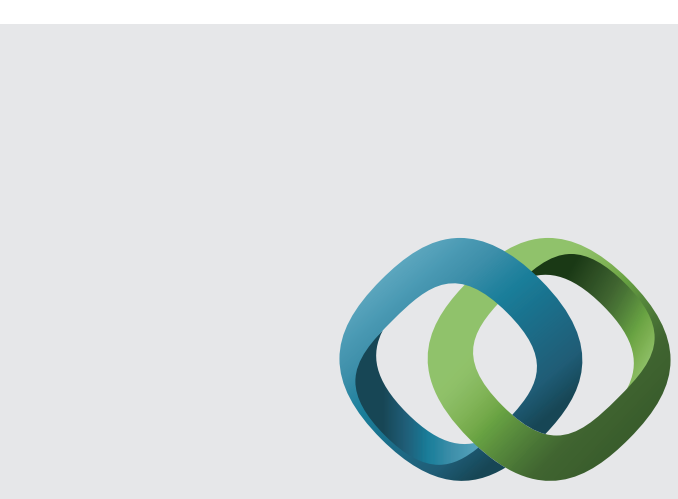

\section{Hindawi}

Submit your manuscripts at

http://www.hindawi.com
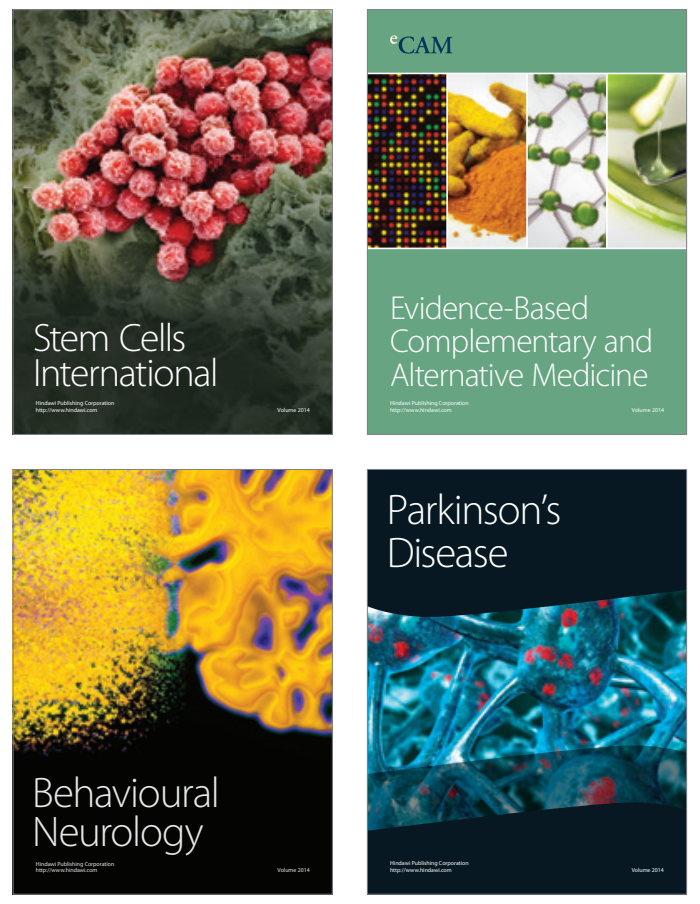
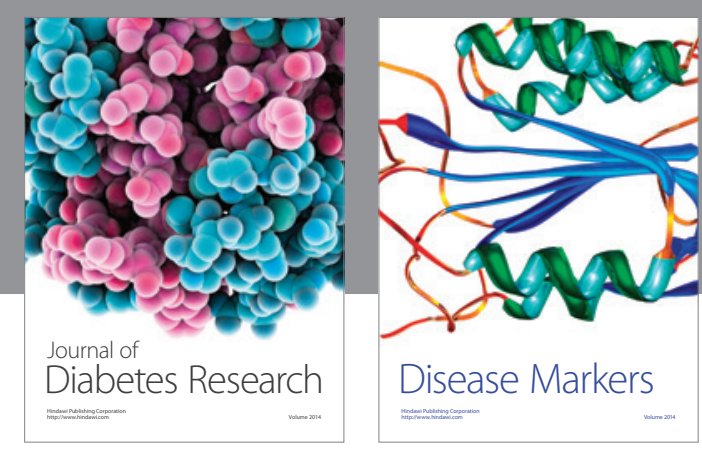

Disease Markers
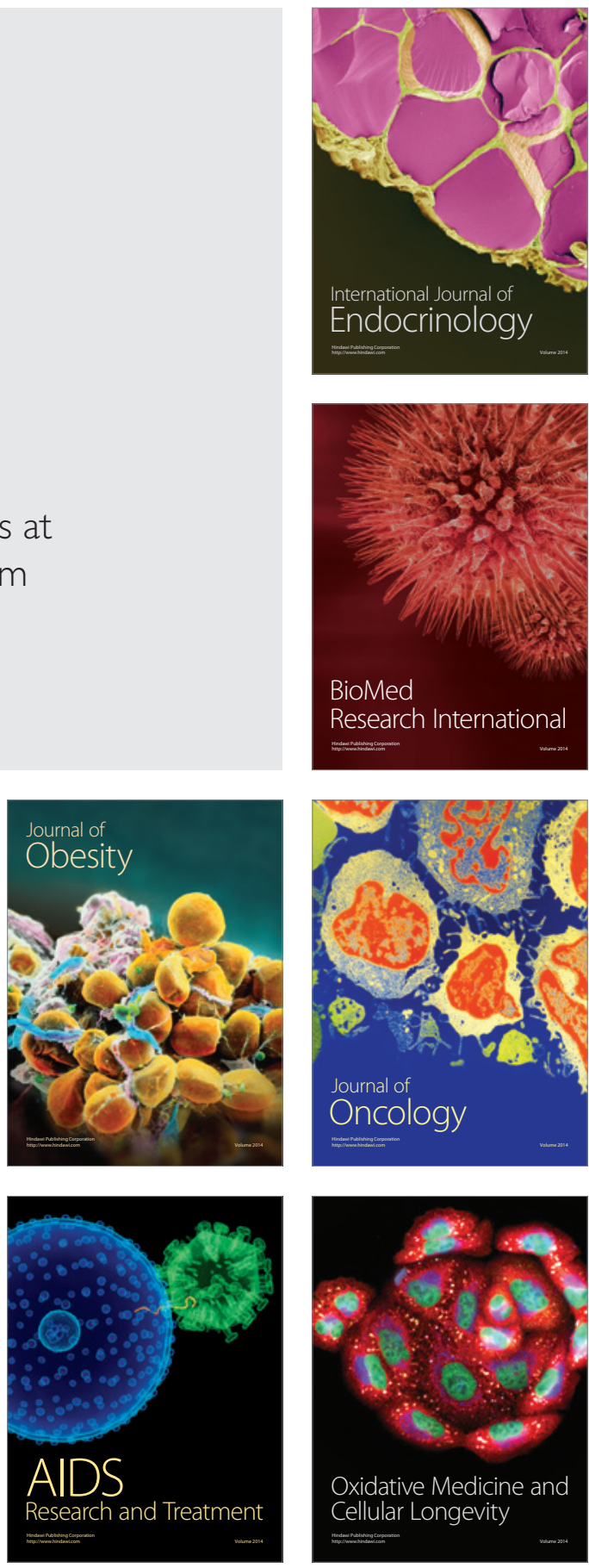